\title{
Open-Field Soilless Culture of Vegetables ${ }^{1}$
}

\section{George Hochmuth and Robert Hochmuth ${ }^{2}$ \\ The Need for Alternative Crop Production Systems}

Commercial vegetable production is very expensive involving many costly inputs. One of these inputs is suitable land, which is becoming scarce, particularly in urbanizing areas around the country. Intensive vegetable production in many areas is being practiced on the same land without regular rotation. Soil fumigants, such as methyl bromide, have provided for continuous vegetable culture in the same fields because these fumigants rid the soil of a broad spectrum of crop pests, including nematodes, insects, weeds, and disease organisms. The combination of polyethylene mulch, drip irrigation, and soil fumigation have provided very efficient, profitable, and safe production of high-quality vegetables around the world (Figure 1). Recently, certain pesticides have been removed from the market and the popular methyl bromide soil fumigant will be phased out by 2005 . With the loss of methyl bromide, vegetable growers will find it more difficult to eradicate certain soil-borne pests and weeds for successful vegetable production.

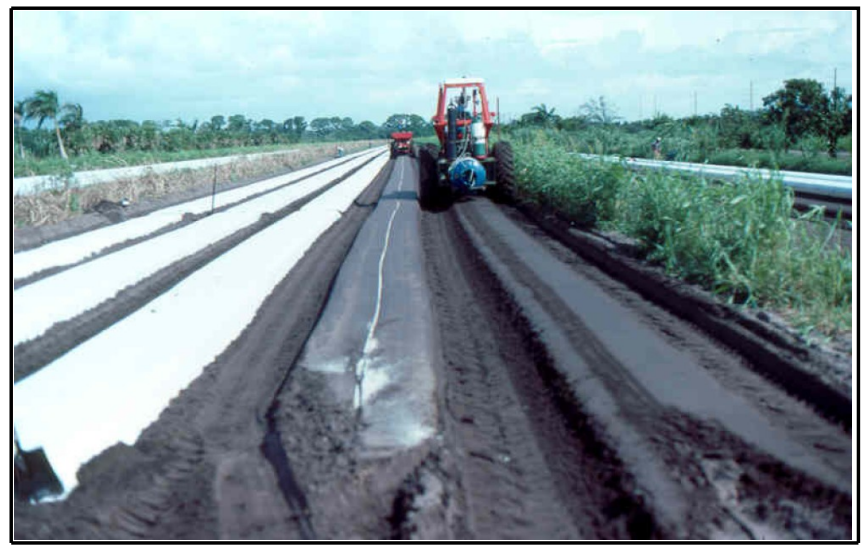

Figure 1. Raised-beds with methyl bromide fumigation and polyethylene mulch has been a standard vegetable production system in Florida.

\section{Soilless Culture as an Alternative System}

Researchers have been evaluating new chemicals and re-evaluating older chemicals to replace methyl bromide. Results from most studies show there is currently no highly suitable, easy, and inexpensive chemical replacement for methyl bromide. For certain crops, special combinations of soil pesticides and herbicides might function as a suitable replacement in selected production systems. For some vegetables, e.g., those produced on relatively small acres or having few pesticides labeled,

1. This document is one of a series of Department of Horticultural Sciences, Florida Cooperative Extension Service, Institute of Food and Agricultural Sciences, University of Florida. Publication date: January 1996. Updated: January 2003. Please visit the EDIS Web site at http://edis.ifas.ufl.edu.

2. George J. Hochmuth, professor and center director, North Florida Research and Education Center, and Robert C. Hochmuth, multi county extension agent, North Florida Research and Education Center - Suwannee Valley, University of Florida, Institute of Food and Agricultural Sciences, Gainesville, FL 32611

The Institute of Food and Agricultural Sciences is an equal opportunity/affirmative action employer authorized to provide research, educational information and other services only to individuals and institutions that function without regard to race, color, sex, age, handicap, or national origin. For information on obtaining other extension publications, contact your county Cooperative Extension Service office. Florida Cooperative Extension Service/Institute of Food and Agricultural Sciences/University of Florida/Christine Taylor Waddill, Dean. 
continued soil-based production will be challenged (Figure 2). Although many potential chemical alternatives to methyl bromide have been evaluated, the options appear to be limited. Soilless culture, such as used in greenhouses (Figure 3) might be a very good alternative to soil-based culture, especially for situations where suitable chemical soil treatments do not exist. In this article, we describe our experiences with soilless culture of vegetables in the open field.

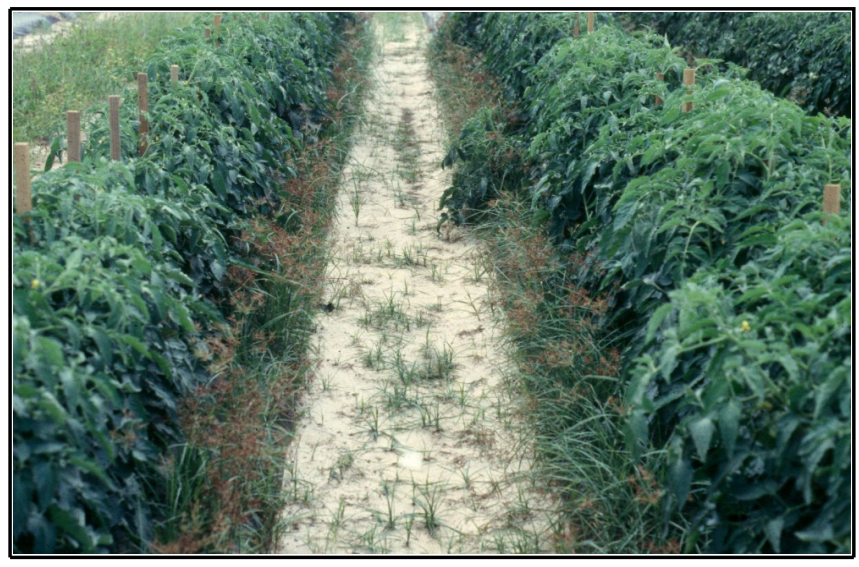

Figure 2. Fields with nutgrass will be a challenge for developing alternative fumigation systems to replace methyl bromide.

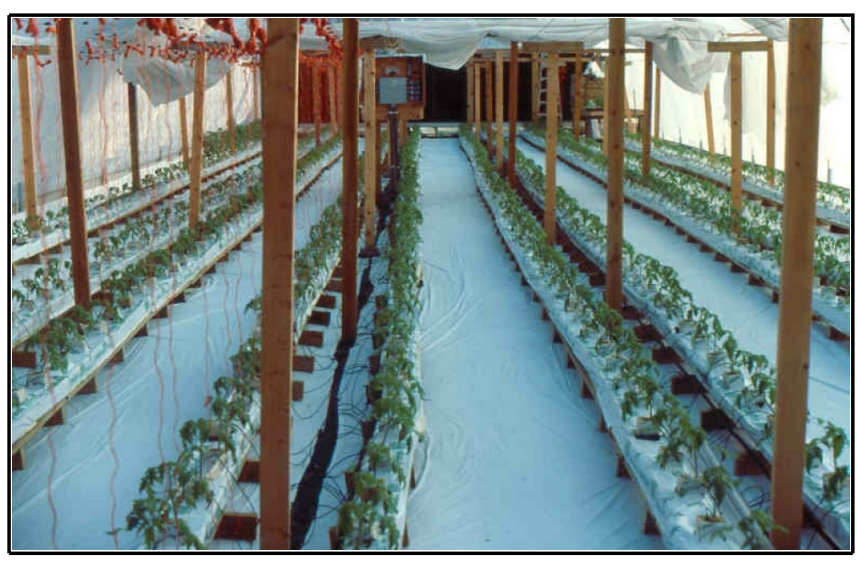

Figure 3. Greenhouse with tomatoes growing in soilless media.

Soilless culture as a crop production system has been used around the world for centuries and is currently relied on heavily in greenhouse vegetable production in Europe, United States, the Middle East, Japan, Canada, among other countries. Many of these soilless systems are referred to as hydroponic culture. Soilless culture is used in greenhouse cultural systems because crop culture is practiced continually in the same site without fumigation. In many areas around the world, greenhouses are sited on native soil that is unsuitable for plant growth. Finally, soilless culture is being more widely practiced because soil fumigation is becoming less practical and more expensive. Greenhouse growers have had many years to adopt soilless culture for vegetable production and many soilless systems have been developed. Early systems relied on naturally available sand, gravel, volcanic rock, or various mixtures of these materials. Nutrient-film systems, involving producing crops in recirculating nutrient solutions, have been used for many years. Modern systems employ manufactured media such as rockwool, perlite, expanded clay, and other materials in plastic containers or plastic wrapping. Certain organic products, such as pine bark, coconut coir, rice hulls, composted plant materials, etc., also are used successfully for greenhouse culture of vegetables. Many of these soilless media systems can be adapted for open-field use, a project we have been working on for several years in Florida.

\section{The Outdoor Lay-flat Bag Soilless System}

We have focused much of our effort on the lay-flat perlite bag soilless system (Figure 4 \& Figure 5). Soilless systems are particularly adapted to small farms producing a variety of crops, but also can be used by growers producing crops in large fields. The following is an outline of important aspects of successful open-field soilless production of vegetables.

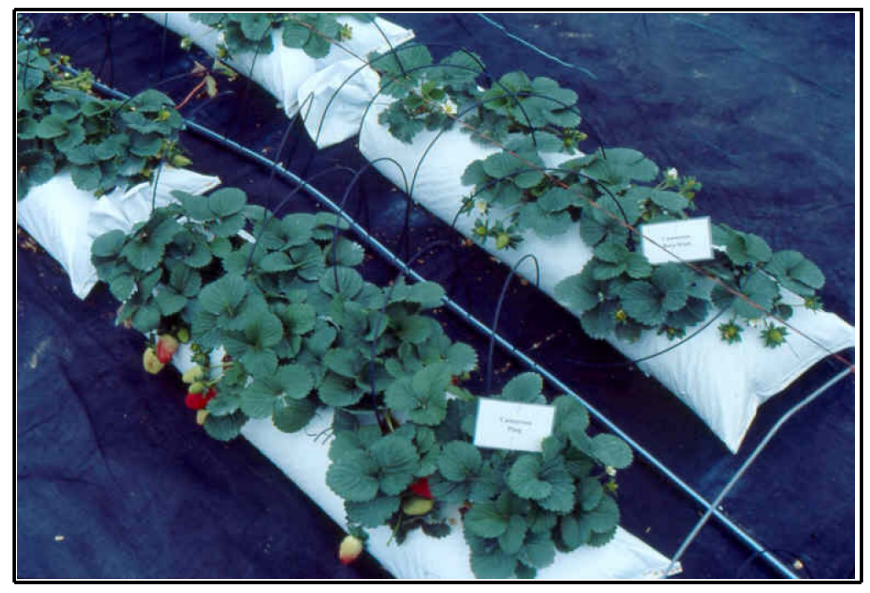

Figure 4. Short lay-flat bags filled with perlite in use for outdoor strawberry production. 


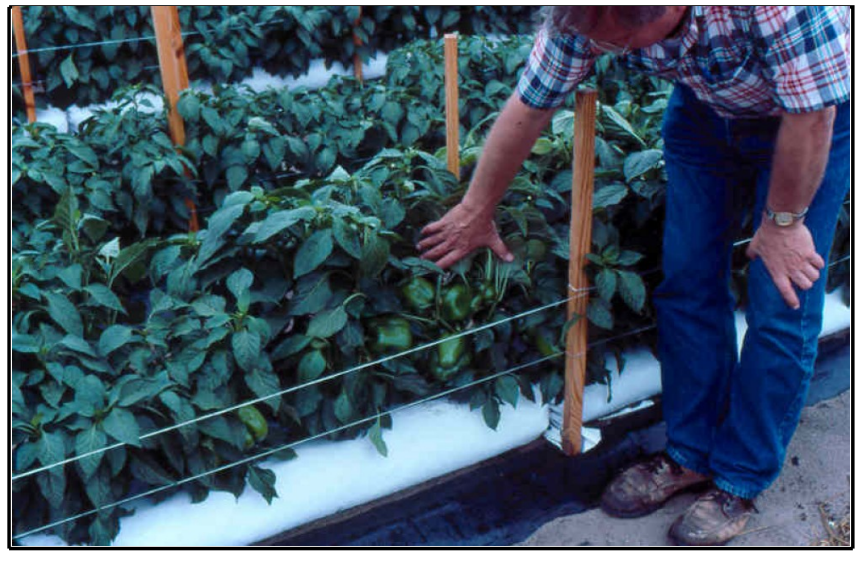

Figure 5. Long lay-flat bags filled with perlite in use for outdoor pepper production.

\section{Field Site}

Soilless culture can be practiced on any field site on the farm, but when possible, growers should chose areas free of weeds such as nutsedge and areas least likely to flood (Figure 6). We have found it preferable to place the soilless bags on polyethylene-mulched raised beds in the field (Figure 7). Raised beds place the bags above the soil reducing the chances for soil contamination of the media and increases air movement and water drainage. An alternative for small production units is to place nursery ground cloth on the ground underneath the bags (Figure $8 \&$ Figure 9).

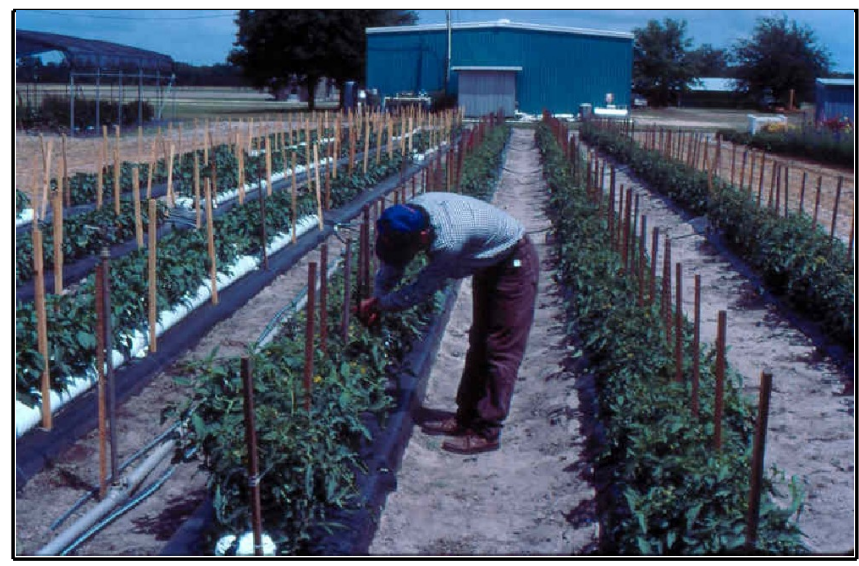

Figure 6. Level, sandy field, with minimal perennial weed problems is ideal for outdoor soilless culture on polyethylene mulched beds.

\section{Irrigation and Nutrient Delivery System}

Nutrients and water are delivered to the crop using similar methods as those used in the

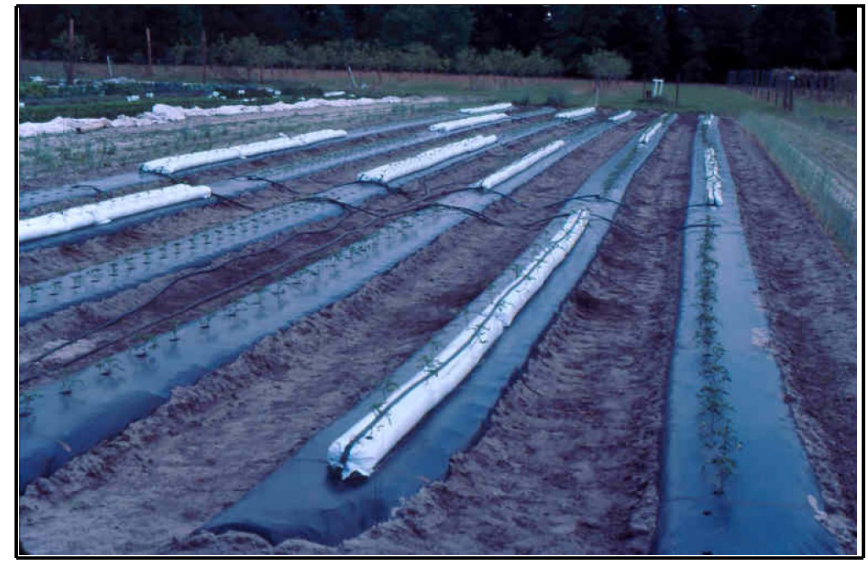

Figure 7. Long, perlite-filled lay-flat bags placed on polyethylene mulched beds in a field, with drip irrigation tube laid on top of the bag.

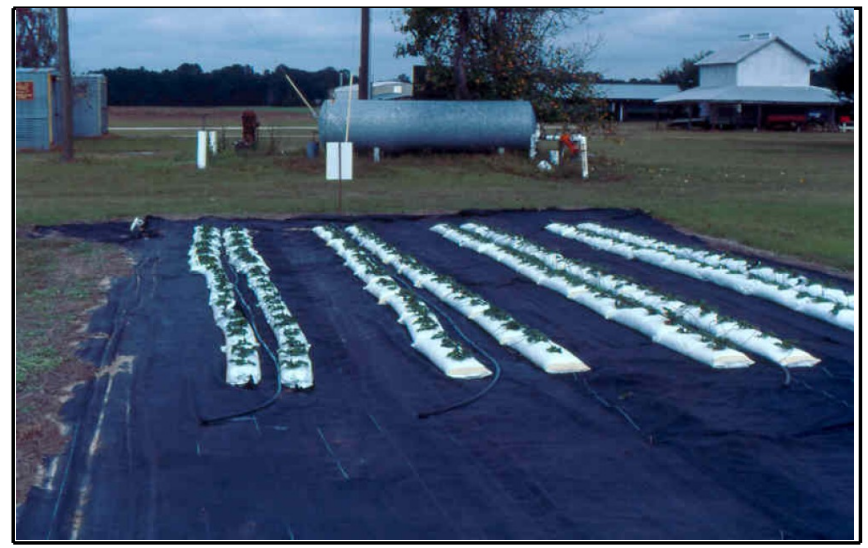

Figure 8. Using black nursery cloth on which to place perlite-filled lay-flat bags for strawberries.

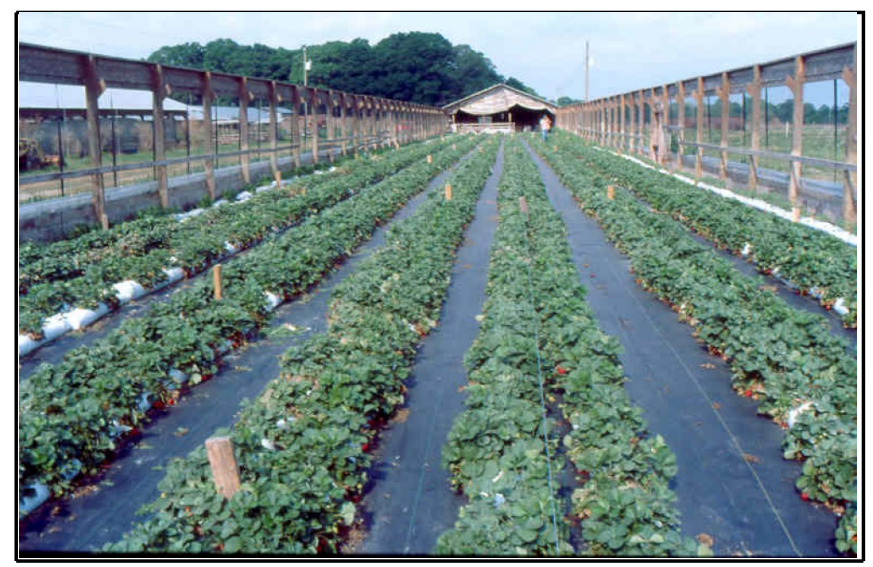

Figure 9. Large-scale strawberry production in perlite-filled bags placed on black nursery cloth.

greenhouse, including polyethylene delivery tubing and micro-irrigation emitters, delivering nutrient solution to each plant. This system is very expensive to install, but can be used for many years. We have been working to adapt the standard drip irrigation tubing for use in this soilless system. We have found 
that the drip irrigation tubing can be placed on top of the bags so the nutrient solution drips into the plant holes in the bags (Figure 7). Also, the drip tubing can be threaded into the bags at the time the bags are placed in the field. For some crops, with vigorous root systems (tomatoes), we have found that it is preferable to place the tubing on top of the bags. If the tubing is placed inside the bags, tomato roots can grow into the tubing emitters causing clogging. A depression should be made in the surface of the bags so the drip tape stays in place and also to help keep nutrient solution from draining off the surface of the bag to the ground. When laying the tubing on the surface of the bags, some system should be employed, such as tape or wire or plastic hooks, to hold the tubing in place. In addition, we have found that it helps to punch extra holes in the bag top to facilitate water entrance to the media. Drainage slits should be placed in the bottom side of the bags after the perlite has been wetted, so excess water can be drained from the media, to prevent root flooding.

\section{Bag Size, Placement, and Spacing}

Bags containing perlite, or other suitable media, can be of any size, with size depending on the preference of the grower. The bags can be filled by the grower or can be purchased pre-filled. Typically, in greenhouse culture, the bags are 3 feet in length and about 15 inches in circumference, each holding about 0.5 cubic feet of media. This same bag can be used outdoors. An option is a longer bag (maybe a continuous bag) that is filled as it is placed in the field (Figure 10). Soilless bags can be placed on the raised bed in single-row fashion for crops such as tomato or melon, or can be placed in twin-row fashion for crops such as pepper, herbs, or cut-flowers. We employ about 12 inches between the bags in the twin-row system and the plant spacing down the row should be that typically used for field culture. Bags are typically made from co-extruded polyethylene with white on the outside and black in the inside. This color arrangement is good for crop production in the southern part of the country or for fall production anywhere. For crops growing in cooler seasons, it might be preferred to have black bags that warm up faster. White latex paint can be sprayed on the bags, and on the black plastic mulch on the raised beds, to create cooler conditions for fall season.

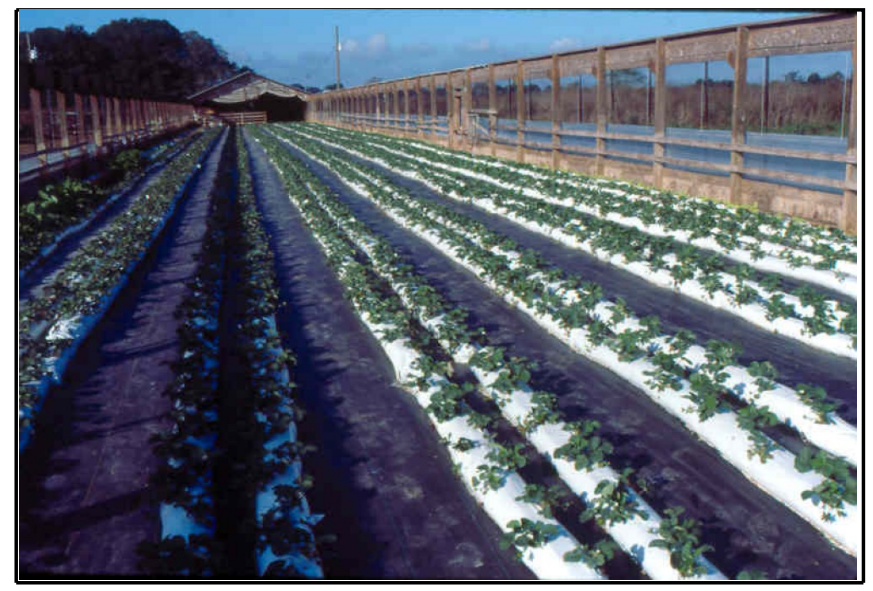

Figure 10. Continuous-filled perlite bags for commercial strawberry production.

\section{Fertilization}

Crops grown in this outdoor soilless system are fertilized with nutrient solutions similar to the approach used in greenhouse systems. Nutrient solution recipes are available from extension workers. The nutrient solution recipes we have been using in our research are published in our Website (http://nfrec-sv.ifas.ufl.edu). Care needs to be exercised so excess solution draining from the bags does not contain large amounts of nutrients, especially nitrogen. Growing crops in soilless culture with nutrients delivered in this fashion when the crop needs them is a very efficient system and leads to reduced waste and loss of fertilizers. Growing turf in the row middle areas would help use any nutrients draining from the bags. Fertilization and nutrient management in soilless systems is a critical part of success and it requires time and careful attention to detail.

\section{Double-Cropping}

We have used the soilless system for continual cropping using the same bags, media, and irrigation system. The media can be used for several crops and the best approach is to grow dissimilar crops in succession, for example melons or squash after tomato or pepper. Cool-season crops such as broccoli can be grown in the same bags used for spring or summer melons. 


\section{Crop Production}

We have had considerable success growing many vegetables in outdoor soilless culture.

Production of strawberry has been increased by $50 \%$ on a field area basis compared to standard soil-based field production (Figure 11). The yield increase comes from the capability of placing more plants per unit area with the soilless system. Tomato and pepper production is increased with the soilless system, largely because of increases in numbers of extra-large fruits (Figure 12 \& Figure 13). The pepper fruit quality has been improved with soilless culture due to thicker fruit walls, probably related to better nutrient management with the soilless system. Nutritional post-harvest quality parameters of soil and soilless based fruits have been similar for tomato and pepper. Other crops that have performed well in outdoor soilless culture include squash, cucumber, and onion (Figure 14).

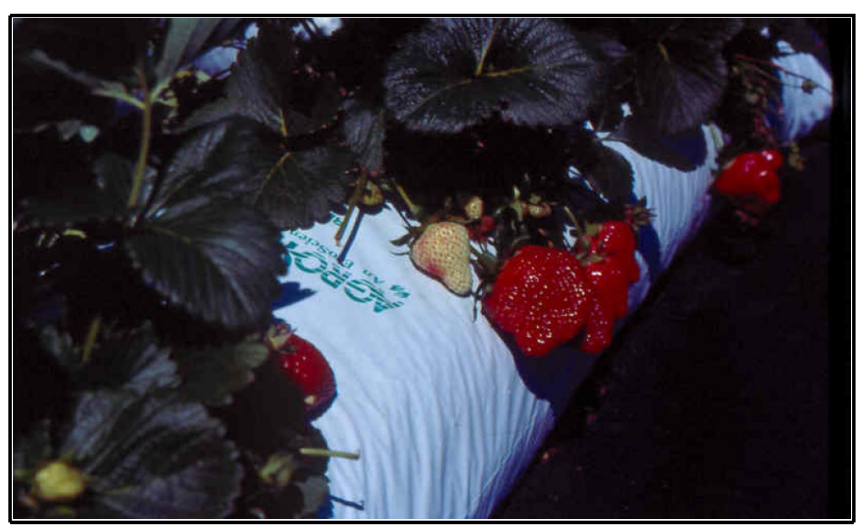

Figure 11. Strawberry production in perlite-filled lay-flat bags.

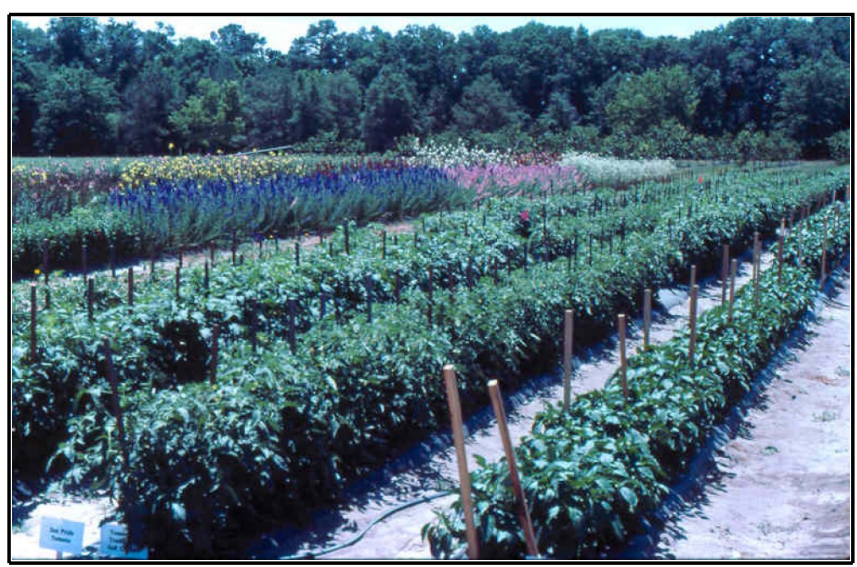

Figure 12. Tomato production in outdoor soilless culture.

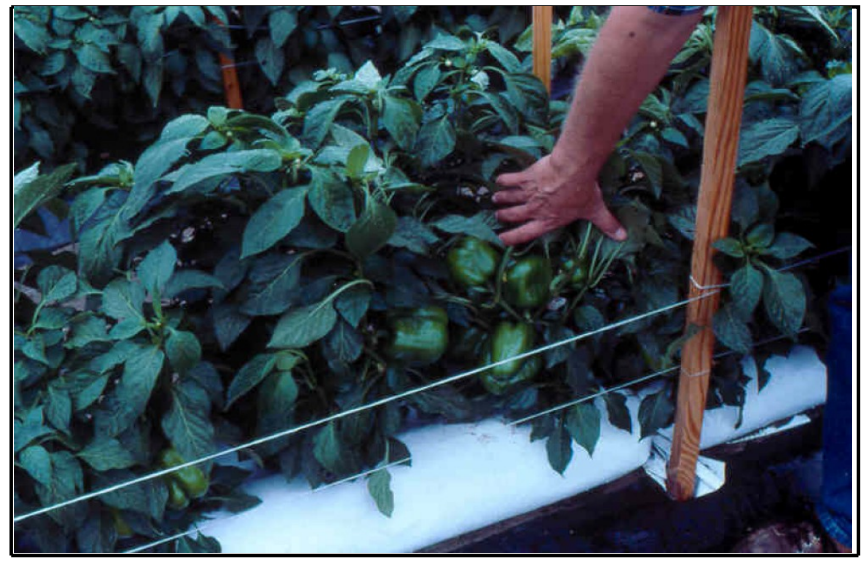

Figure 13. Pepper production in outdoor soilless culture.

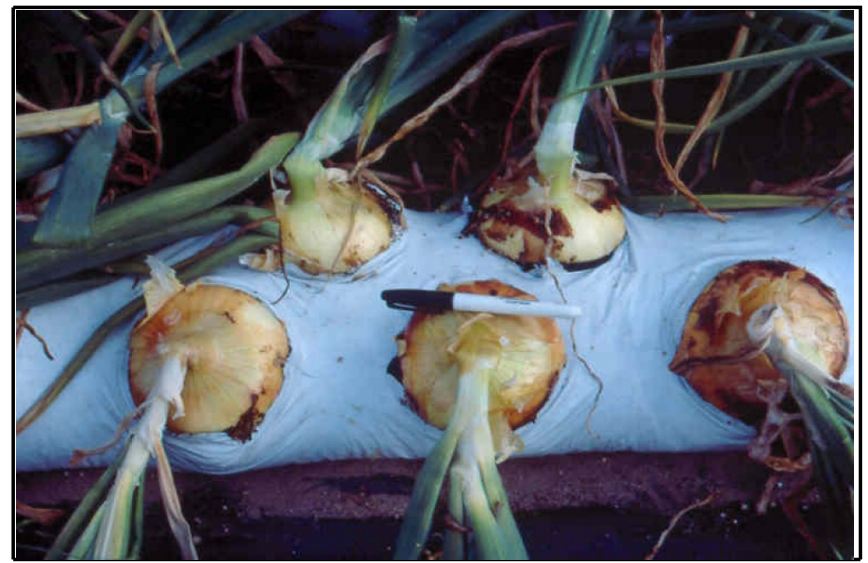

Figure 14. Sweet onion production in perlite-filled lay-flat bags.

\section{Economic Considerations}

Any soilless culture system will involve increased costs for installation in the field, mostly involving the soilless media, installation labor, and the irrigation system. We are evaluating the economics resulting from our work with the crop production, but it is clear that soilless culture will be most adaptable for high-value crops and for systems where increased income can result from improved fruit quality. Outdoor soilless culture is easily adapted by the small farmer producing a variety of crops, especially for direct-marketing. 